\title{
The comparative study to evaluate the effect of palonosetron monotherapy versus palonosetron with dexamethasone combination therapy for prevention of postoperative nausea and vomiting
}

\author{
Jung Woo Park, Jin Woo Jun, Yun Hee Lim, Sang Seok Lee, Byung Hoon Yoo, Kye-Min Kim, \\ Jun Heum Yon, and Ki Hyuk Hong \\ Department of Anesthesiology and Pain Medicine, Sanggye Paik Hospital, Inje University College of Medicine, Seoul, Korea
}

Background: 5-hydroxytryptamine type 3 (5-HT3) receptor antagonists are effective and safe on postoperative nausea and vomiting (PONV). Palonosetron, the newest 5-HT3 antagonist, has potent antiemetic property. We hypothesized that a combination of palonosetron and dexamethasone could more decrease PONV than palonosetron alone.

Methods: Among the patients scheduled to undergo laparoscopic gynecologic surgery, mastoidectomy with tympanoplasty or thyroidectomy under general anesthesia, eighty four female patients with at least two PONV risk factors were enrolled in this study. They were received randomly $0.075 \mathrm{mg}$ palonosetron and $4 \mathrm{mg}$ dexamethasone (group C) or $0.075 \mathrm{mg}$ palonosetron alone (group P). The severity of PONV using Rhodes index and the percentage of complete response during postoperative 24 hours were compared between groups.

Results: The frequency of mild/moderate/great/severe PONV based on Rhodes index were 9.8\%/0\%/0\%/0\% and 9.3\%/2.3\%/2.3\%/0\% in group P and group C, respectively. Complete response for PONV was observed in $90.2 \%$ and $86 \%$ of patients in group P and group C, respectively. The overall incidence of PONV in group P and C was 9.8\% and $14 \%$, respectively. There was no significant difference between the two groups.

Conclusions: There were no differences between palonosetron monotherapy and combination therapy of palonosetron and dexamethasone in patients with high emetogenic risk. (Korean J Anesthesiol 2012; 63: 334-339)

Key Words: Dexamethasone, Palonosetron, PONV

Received: January 20, 2012. Revised: 1st, March 27, 2012; 2nd, April 17, 2012; 3rd, April 25, 2012. Accepted: April 26, 2012.

Corresponding author: Jun Heum Yon, M.D., Ph.D., Department of Anesthesiology and Pain Medicine, Sanggye Paik Hospital, Inje University College of Medicine, 761-1, Sanggye 7-dong, Nowon-gu, Seoul 139-707, Korea. Tel: 82-2-950-1173, Fax: 82-2-950-1323, E-mail: yonjh@paik.ac.kr (c) This is an open-access article distributed under the terms of the Creative Commons Attribution Non-Commercial License (http:// creativecommons.org/licenses/by-nc/3.0/), which permits unrestricted non-commercial use, distribution, and reproduction in any medium, provided the original work is properly cited. 


\section{Introduction}

Postoperative nausea and vomiting (PONV) is one of the most common complaints following operations and anesthesia. PONV is the main factor for decreased patient satisfaction and can cause delayed recovery. Moreover, although rare it can result in morbidity such as wound dehiscence, pulmonary aspiration, dehydration, and esophageal rupture. Factors that reportedly affect the incidence of PONV include female sex, non-smoker, history of PONV, motion sickness, lengthy surgical duration, inhalational anesthetics, nitrous oxide, intra-operative and post-operative use of opioids. In addition, severe anxiety prior to surgery, the type of surgery, intra-operative fluid therapy, and increased duration of anesthesia. also affect the incidence of PONV [1]. Female gender, motion sickness, history of PONV, non-smoker, and post-operative use of opioids are known to be the most predictive factors among all the factors. If no risk factors are present, the incidence of PONV is about $10 \%$. However, the incidence of PONV has been reported to rise to $21,39,61 \%$, and $79 \%$ as the risk factors increase one by one [2].

5-HT3 receptor antagonists have been used since they were first proven to be highly effective in preventing postoperative nausea and vomiting [3]. Palonosetron is the most recently developed 5-HT3 antagonist and its efficacy was first proven in the prevention of chemotherapy induced nausea and vomiting (CINV). It is a second-generation 5-HT3 antagonist and has a different chemical structure and a longer half-time (about 40 hours) compared to other 5-HT3 antagonists such as ondansetron, dolasetron, and granisetron [4-7].

Palonosetron $(0.075 \mathrm{mg})$ was proven to be effective in early PONV (0-24 hours postoperatively) and in delayed PONV (24-72 hours postoperatively). When it comes to early PONV prevention, palonosetron is known to reduce the incidence of PONV by $20 \%$ to $30 \%$ compared to antiemetics such as ondansetron, dexamethasone, and droperidol [8]. Combination drug therapy, which uses the 5-HT3 receptor antagonists and one of dexamethasone, droperidol or promethazine for high-risk groups, significantly reduces the incidence of PONV compared to monotherapy $[9,10]$. The combination of dexamethasone with one of ondansetron, dolasetron, granisetron or tropisetron reduce the incidence of PONV in high-risk groups, and it does not lead to prolonged QT intervals on the EKG or torsades de pointes, proving its safety $[9,11]$.

However, there are no studies regarding the efficacy of the combination of palonosetron with dexamethasone as opposed to its monotherapy. As a result, in this study, we compared the efficacy of combination therapy and monotherapy in preventing PONV.

\section{Materials and Methods}

This study protocol was approved by the institutional review board and informed written consent was obtained from the patients. This study targeted female patients with American Society of Anesthesiologists physical status 1-2, who were aged 18-60 years, and were scheduled to undergo laparoscopic gynecologic surgery, mastoidectomy with tympanoplasty or thyroidectomy.

There was no significant difference in age, postoperative nausea and vomiting, or motion sickness, medical history, smoking history, types of surgeries, and duration of anesthesia between the two groups (Table 1). We included patients with two risk factors or more, among which were female gender, nonsmoking status, history of PONV, and/or motion sickness, according to the suggestion by Apfel et al. [2]. Patients who asked for patient controlled analgesia using opioids were excluded. Patients with difficulties in receiving intubation, pregnant women, patients with psychiatric disorders, patients who were clinically ill with intestinal disease, and patients who took antiemetic drugs 24 hours preoperatively were also ruled out. In cases where unexpected blood loss occurred, laparoscopy was converted to a laparotomy, or open surgery, and were excluded. We targeted patients transferred to a ward from a postanesthesia care unit, and ruled out patients transferred to an intensive care unit after surgery, patients who underwent day surgery, and patients who were not able to communicate.

Patients were kept fasting for eight hours on the day of surgery and were administered glycopyrrolate $(0.2 \mathrm{mg})$ via intramuscular injection 30 minutes prior to surgery as a pre-

Table 1. Characteristics of Patients

\begin{tabular}{lcc}
\hline & $\begin{array}{c}\text { Group P } \\
(\mathrm{n}=41)\end{array}$ & $\begin{array}{c}\text { Group C } \\
(\mathrm{n}=43)\end{array}$ \\
\hline Age (yr) & $39.9 \pm 10.8$ & $38.4 \pm 11.4$ \\
PONV history and/or currently & 10 & 14 \\
prone to motion sickness* & & 40 \\
Smoking status non-smoker* & 34 & $56.6 \pm 8.2$ \\
Weight (kg) & $59.1 \pm 10.4$ & $158.7 \pm 5.6$ \\
Height (cm) & $159.4 \pm 5.1$ & 26 \\
Type of surgery* & 27 & 3 \\
Laparoscopic & 11 & 40 \\
Tympanoplasty \& mastoidectomy & 3 & 3 \\
Thyroidectomy & & 8 \\
ASA physical status* & 39 & $123.1 \pm 45.5$ \\
1 & 2 & 8 \\
2 & $117.1 \pm 42.0$ & \\
Duration of anesthesia (min) & 9 & \\
Postoperative opioids usage & & \\
\hline
\end{tabular}

Group P: Palonosetron 0.075mg, Group C: Palonosetron $0.075 \mathrm{mg}$ and dexamethasone $4 \mathrm{mg}$. *Data are mean \pm SD or number of patients. 
medication. They were randomly allotted to group $\mathrm{P}$ and group C. Patients in group $\mathrm{P}$ were administered palonosetron $(0.075 \mathrm{mg})$ five minutes before anesthesia and patients in group $\mathrm{C}$ were administered both palonosetron $(0.075 \mathrm{mg})$ and dexamethasone ( $4 \mathrm{mg}$ ) via intravascular injection. The total volume of medication increased to $3 \mathrm{ml}$ by diluting them with normal saline, and it was intravenously injected into the patients.

Anesthesia in all groups was induced with lidocaine (40 mg) and propofol ( $2 \mathrm{mg} / \mathrm{kg}$ ) via IV and intubation was performed with rocuronium $(0.6 \mathrm{mg} / \mathrm{kg})$ via $\mathrm{IV}$, and anesthesia was maintained by sevoflurane, using air $(2.5 \mathrm{~L} / \mathrm{min})$ and oxygen (1.5 L/min). End tidal carbon dioxide partial pressure was maintained at $35 \pm 3 \mathrm{mmHg}$ and the patient's pulse rate and blood pressure was sustained within $20 \%$ of previously recorded numbers. During surgery, Hartmann's solution was injected at a regular pace $(10 \mathrm{ml} / \mathrm{kg} / \mathrm{hr})$ via IV infusion.

With injection of pyridostigmine and glycopyrrolate at the completion of the surgery, we counteracted the effect of the muscle relaxant. Patients who had scores of 50 or more out of 0-100 $\mathrm{mm}$ on the Visual Analogue Scale were intravenously injected with $30 \mathrm{mg}$ of ketorolac in an attempt to control pain. We injected ondansetron ( $4 \mathrm{mg}$ ) via IV for patients who complained of nausea more than twice or vomited within 15 minutes after the completion of surgery.

Nausea was defined as an unpleasant sensation associated with the urge to vomit, and vomiting was defined as the case when the gastric contents were thrown up into the mouth by passing through the esophagus and pharynx, and retching was defined as the reverse movement of the stomach without vomiting. We evaluated PONV by using the Rhodes index (Rhodes index of nausea, vomiting and retching, RINVR), which was standardized by Rhodes, the $0-100$ mm VAS score, and the complete response (no postoperative nausea and vomiting, and no requirement for rescue antiemetics) at the time of 2 hours and 24 hours after the extubation.

We obtained the RINVR score after assessing the postoperative nausea and vomiting using the Rhodes questionnaire (Table 2). The paper had eight questions on a scale of $0-4$ with one being the lowest level without any symptoms related to nausea and vomiting and four being the highest level.

PONV was assessed by RINVR total experience scores shown in Table 2. Scores of $1-8,9-16,17-24$, and 25-32 were categorized as mild, moderate, great, and severe, respectively [12]. An anesthesiologist who was not related to this survey and did not know the subjects recorded the Rhodes index, 0-100 mm VAS score, and complete response on the questionnaires at the ward during the allotted time in order to assess PONV.

We assumed that complete response would occur in $43 \%$ based upon the study result in which the complete response for PONV was $43 \%$ after a single injection of palonosetron [13], and postulated that the complete response for the combination of palonosetron with dexamethasone would be $70 \%$. According to the assumptions, we identified the subjects we needed for the study. In $\alpha=0.05,(1-\beta)=0.8,41$ patients in each group who showed more than a $25 \%$ difference in complete response between the monotherapy with palonosetron and the combination therapy with palenosetron and dexamethasone were required.

We used GraphPad Prism (version 5.00 for Windows,

Table 2. Rhodes Index of Nausea, Vomiting and Retching (RINVR)

1. In the last 2, 24 hours, I threw up ( ) times. 7 or more

2. In the last 2, 24 hours, from retching and dry heaves, I have felt ( ) distress.

3. In the last 2, 24 hours, from vomiting or throwing up, I have felt ( ) distress.

4. In the last 2, 24 hours, I have felt nauseated or sick to my stomach.

5. In the last 2, 24 hours, from nausea/sickness to my stomach, I have felt ( ) distress.

6. In the last 2, 24 hours, each time I threw up, I produced a ( ) amount.

7. In the last 2, 24 hours, I have felt nauseated or sick to my stomach ( ) times.

8. In the last 2, 24 hours, I have had periods of retching or dry heaves without bringing anything up ( ) times.
(4)

$5-6$

(3)

No

(0)

Severe

(4)

Not at al

(0)

No

(0)

Very large

( 3 cups or more)

(4)

7 or more

(4)

No

(0)
Mild

(1)

Great

(3)

1 hour or less

(1)

Mild

(1)

Large

(2-3 cups)

(3)

5-6

(3)

$1-2$

(1)
3-4

(2)

Moderate

(2)

Moderate

(2)

$2-3$ hours

(2)

Moderate

(2)

Moderate

(1/2-2 cups)

(2)

3-4

(2)

3-4

(2)
$1-2$

reat

(3)

Mild

(1)

4-6 hours

(3)

Great

(3)

Small

(up to $1 / 2$ cups)

(1)

1-2

(1)

5-6

(3)
I did not

throw up

(0)

Severe

(4)

No

(0)

More than

6 hours

(4)

Severe

(4)

I did not

throw up

(0)

No

(0)

7 or more

(4)

Total experience score: sum of all scores, total occurrence score: $1+4+6+7+8$, total distress score: $2+3+5$. 
GraphPad Software, San Diego California, USA, www.graphpad. com) for statistical analysis and marked all scorers with the median \pm standard deviation. The frequency was marked with $\%$ (the number of the patients). Parametric scores such as age, weight, height, and duration of anesthesia in each group were analyzed by student's t-test, and non-parametric scores such as patients' characteristics and medical history were assessed by the Mann-Whitney test. We utilized a chi-square test and Fisher's exact test, when comparing the incidence of PONV and

Table 3. Incidences of Nausea, Vomiting, and Severity of Nausea during the First 24 Hours after Surgery

\begin{tabular}{lcc}
\hline & $\begin{array}{c}\text { Palonosetron } \\
(\mathrm{n}=41)\end{array}$ & $\begin{array}{c}\text { Palonosetron }+ \\
\text { dexamethasone } \\
(\mathrm{n}=43)\end{array}$ \\
\hline $0-2 \mathrm{hr}$ & $3(7.3)$ & $5(11.6)$ \\
Nausea & 0 & 0 \\
Vomiting & 0 & 0 \\
Nausea \& vomiting & $3.17 \pm 11.5$ & $6.51 \pm 19.63$ \\
VAS for nausea* & $1(2.4)$ & $2(4.7)$ \\
$2-24$ hr & 0 & $1(2.3)$ \\
Nausea & 0 & $1(2.3)$ \\
Vomiting & $1.22 \pm 7.81$ & $2.56 \pm 12.93$ \\
Nausea \& vomiting & & \\
VAS for nausea & $4(9.8)$ & $6(14)$ \\
Total & 0 & $1(2.3)$ \\
Nausea & 0 & $1(2.3)$ \\
Vomiting & $4.39 \pm 13.61$ & $7.21 \pm 19.92$ \\
Nausea \& vomiting & & \\
VAS for nausea & &
\end{tabular}

Data are mean \pm SD or number of patients (\%). VAS: visual analogue scale. *VAS score for nausea (0: none, 100: the worst imaginable nausea).

Table 4. Severity of Postoperative Nausea and Vomiting Based on the RINVR Scores during the First 24 Hours after Surgery

\begin{tabular}{lcc}
\hline & $\begin{array}{c}\text { Palonosetron } \\
(\mathrm{n}=41)\end{array}$ & $\begin{array}{c}\text { Palonosetron }+ \\
\text { dexamethasone }(\mathrm{n}=43)\end{array}$ \\
\hline $0-2 \mathrm{hr}$ & $3(7.3)$ & $3(7)$ \\
Mild & 0 & $1(2.3)$ \\
Moderate & 0 & $1(2.3)$ \\
Great & 0 & 0 \\
Severe & & \\
$2-24 \mathrm{hr}$ & $1(2.4)$ & $1(2.3)$ \\
Mild & 0 & $1(2.3)$ \\
Moderate & 0 & 0 \\
Great & 0 & 0 \\
Severe & & \\
Total & $4(9.8)$ & $4(9.3)$ \\
Mild & 0 & $1(2.3)$ \\
Moderate & 0 & $1(2.3)$ \\
Great & 0 & 0 \\
Severe & 0 &
\end{tabular}

Data are number of patients (\%). The severity of PONV was assessed based on the experience scores of RINVR (Rhodes index of nausea, vomiting and retching) as follows. 1-8: mild, 9-16: moderate, 1724: great, $25-32$ : severe. the complete response rate between the two groups. A P value of $<0.05$ was considered statistically significant.

\section{Results}

This study was carried out with a total of 84 patients. The incidence rate of PONV two hours after surgery was $7.3 \%$ (three persons) in group $\mathrm{P}$, and $11.6 \%$ (five persons) in group $\mathrm{C}$. The incidence of PONV was $2.4 \%$ (one person) in group $\mathrm{P}$, and $4.7 \%$ (two persons) in group $\mathrm{C}$ from 2-24 hours postoperatively. There was no significant difference in terms of the incidence of PONV between the two groups (Table 3).

As far as vomiting, the VAS score also did not have any significant difference between the two groups over 24 hours postoperatively (Table 4). The complete response was $90.2 \%$ (37 persons) in group $\mathrm{P}$, and $86 \%$ (37 persons) in group C over 24 hours postoperatively with no meaningful statistical difference (Fig. 1).

\section{Discussion}

In this study, the combination of palonosetron with dexamethasone did not significantly reduce the incidence of PONV over 24 hours postoperatively compared to monotherapy with palonosetron (group C versus group P: 14\% versus 9.8\%).

Henzi et al. [11] compared the combination of dexamethasone with 5-HT3 receptor antagonists (ondansetron or granisetron) to the monotherapy of 5-HT3 receptor antagonist. They reported that the occurrence of nausea was $4 \%$ and $11 \%$ over 6 hours postoperatively, and the occurrence of vomiting

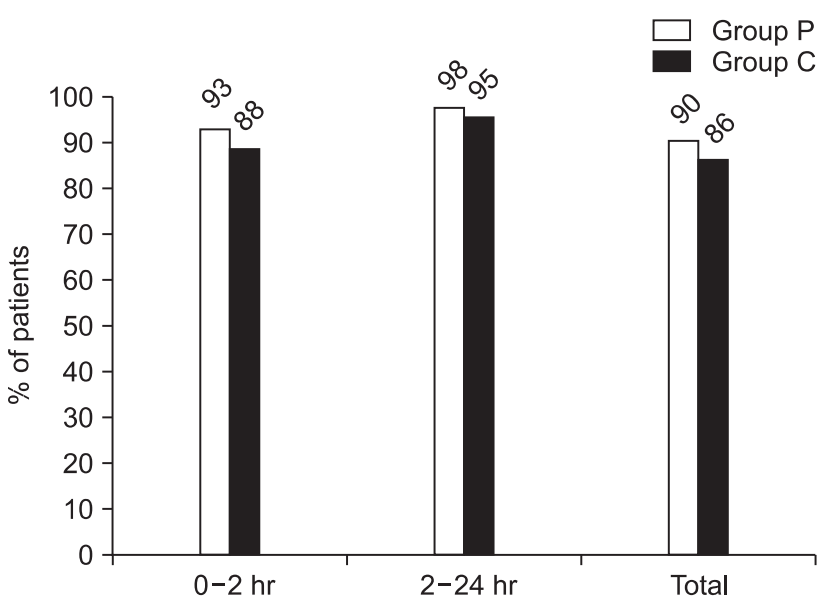

Fig. 1. The complete response (no emesis and no rescue medications) rate of postoperative nausea and vomiting. In group $\mathrm{P}, 0.075 \mathrm{mg}$ of palonosetron was administered. In group C, $0.075 \mathrm{mg}$ of palonosetron and $4 \mathrm{mg}$ of dexamethasone were administered. There are no statistically significant differences between groups at $0-2$ hour, 2-24 hour, 0-24 hour $(\mathrm{P}>0.05)$. 
was $2 \%$ and $7 \%$, respectively. In addition, the occurrence of nausea during 6-24 hours was $28 \%$ for the combination therapy and $41 \%$ for the monotherapy, and the occurrence of vomiting was $23 \%$ and $35 \%$, respectively, reporting a significant difference. Ramosetron and dolasetron, as well as ondansetron or granisetron, are known to be effective in preventing PONV when used in combination with dexamethasone $[14,15]$. The mechanism for antiemetic effects remains unclear, but it is postulated that antiemetics inhibit the secretion of prostaglandin synthesis and endogenous opioids, resulting in a central antiemetic effect [11]. However, in this study, the combination of palonosetron with dexamethasone did not show a considerable difference compared to monotherapy with palonosetron. In this regard, we postulated that monotherapy with palonosetron was fully effective in preventing PONV.

In contrast, another study showed that the combination of dexamethasone with a 5-HT3 receptor antagonist resulted in more headaches, dizziness, drowsiness, sedation, constipation, and muscle pain compared to monotherapy with 5-HT3 receptor antagonist [11]. In that study, only one patient receiving the combination therapy complained of nausea and vomiting along with dizziness. However, the patient complained of dizziness while rising to their feet from the sitting position, which made it difficult to determine if dizziness was associated with the combinatorial use of dexamethasone. In addition, we were not certain whether nausea and vomiting were caused by dizziness or PONV. Palonosetron was reportedly effective in preventing CINV at an acute $(1-24 \mathrm{~h}$ ) phase and a delayed $(24-120 \mathrm{~h})$ phase as opposed to the previously developed 5-HT3 receptor antagonist. The delayed phase CINV is associated with substance $\mathrm{P}$ acting on the NK-1 receptors, and it was reported that NK-1/5-HT3 crosstalk triggers the efficacy of palonosetron [16]. Palonosetron is known to be effective at a delayed phase of PONV [8], and it is thought to be interactive with other factors like NK-1/5-TH3 as well as had a lengthy half-life. In this study, the effect of palonosetron was only evaluated at an acute phase of PONV over 24 hours postoperatively, and a comparative analysis was not made between the monotherapy and the combination therapy at the delayed phase of PONV.

In this study, we excluded patients who had two or more risk factors of PONV suggested by Apfel and who had received surgeries known to increase the risk of PONV such as laparoscopic gynecologic surgery, mastoidectomy with tympanoplasty or thyroidectomy [1]. Despite the exclusion, the complete response for antiemetic drugs (the monotherapy with palonosetron and the combination therapy with it) were high in group P: $90.2 \%$ (37 persons) and group C: $86 \%$ (37 persons). Kovac et al. reported that the complete response for PONV was $56 \%$ in patients injected with palonosetron $(0.075 \mathrm{mg})$ over 24 hours postoperatively, and it reportedly was $43 \%$ in studies conducted by Candiotti and others [13,17]. A lower incidence of PONV in this study compared to studies conducted by Kovac and Candiotti et al. seemed to be associated with the different anesthesia, and the different frequency of opioid use and so on. We did not utilize nitrogen dioxide in this study, while Kovac et al. and Candiotti et al. used 50\% nitrogen dioxide, which increases the likelihood of PONV along with inhalation anesthetic, when maintaining anesthesia. Forty-five percent of the patients in the research conducted by Kovac et al. were postoperatively injected with opioids, but only $20 \%$ of the patients were injected with opioids postoperatively in this study. In addition, the difference in race between the various study subjects could be one of the factors that influence the complete response for PONV. Reitze et al. [18] reported that black South Africans have a lower risk of PONV compared to other races, and claimed that further research regarding the linkage between races and the frequency of PONV should be conducted. As a result, we can assume that there might be a difference in the incidence of PONV between our study and their research which targeted western people.

In this study, Hartmann's solution was administered at a regular pace $(10 \mathrm{ml} / \mathrm{kg} / \mathrm{hr})$ via IV in order to equalize one of the factors that could affect the incidence of PONV. Yoon et al. [19] reported that there was no significant difference in the incidence of PONV between the group injected with a small volume of fluid $(6 \mathrm{ml} / \mathrm{kg} / \mathrm{hr})$ and the group injected with a large volume of fluid (18 ml/kg.hr). Otherwise, in a study conducted by Magner et al. [20], patients receiving laparoscopic gynecological surgeries were divided into two groups according to the volume of Hartmann's solution: a group with a large volume of solution $(30 \mathrm{ml} / \mathrm{kg})$ and a group with a small volume of solution $(10 \mathrm{ml} / \mathrm{kg})$. The results showed that a large volume of fluid injection considerably reduced the incidence of PONV over 48 hours postoperatively. In this study, we equalized the volume of solution intraoperatively administered to the patients; therefore, the effect of the solution on PONV seems to be similar between the two groups. However, there might be a difference between the volume of solution given to patients during fasting periods prior to surgery and the postoperative period.

Laparoscopic gynecologic surgery, mastoidectomy with tympanoplasty, thyroidectomy, and other surgeries were included in this study. Otolaryngological surgery, or ENT surgery can increase the likelihood of PONV four-six fold compared to a reference group, and the incidence increases by three times for gynecological surgery, since the type of surgery affects the incidence of PONV [21]. This study has the limitation of various surgeries being performed, instead of one type of surgery. However, in terms of the type of surgery, no significant difference was found between the two groups; thus, it is 
postulated that it barely has an effect on assessing the efficacy of antiemetic drugs.

In conclusion, the combination therapy of palonosetron with dexamethasone and the monotherapy of palonosetron did not have any differences in patients with high risk factors for preventing postoperative nausea and vomiting.

\section{Acknowledgments}

This work was supported by the 2011 Inje University research grant.

\section{References}

1. Gan TJ. Risk factors for postoperative nausea and vomiting. Anesth Analg 2006; 102: 1884-98.

2. Apfel CC, Laara E, Koivuranta M, Greim CA, Roewer N. A simplified risk score for predicting postoperative nausea and vomiting: conclusions from cross-validations between two centers. Anesthesiology 1999; 91: 693-700.

3. Wilhelm SM, Dehoorne-Smith ML, Kale-Pradhan PB. Prevention of postoperative nausea and vomiting. Ann Pharmacother 2007; 41: 68-78.

4. Wong EH, Clark R, Leung E, Loury D, Bonhaus DW, Jakeman L, et al. The interaction of RS 25259-197, a potent and selective antagonist, with 5-HT3 receptors, in vitro. Br J Pharmacol 1995; 114: 851-9.

5. Miller RC, Galvan M, Gittos MW, van Giersbergen PLM, Moser PC, Fozard JR. Pharmacological properties of dolasetron, a potent and selective antagonist at 5-HT3 receptors. Drug Dev Res 1993; 28: 8793.

6. Gan TJ. Selective serotonin 5-HT3 receptor antagonists for postoperative nausea and vomiting: are they all the same? CNS Drugs 2005; 19: 225-38.

7. Stoltz R, Cyong JC, Shah A, Parisi S. Pharmacokinetic and safety evaluation of palonosetron, a 5-hydroxytryptamine-3 receptor antagonist, in U.S. and Japanese healthy subjects. J Clin Pharmacol 2004; 44: 520-31.

8. Muchatuta NA, Paech MJ. Management of postoperative nausea and vomiting: focus on palonosetron. Ther Clin Risk Manag 2009; 5: 21-34.

9. Gan TJ, Meyer T, Apfel CC, Chung F, Davis PJ, Eubanks S, et al. Consensus guidelines for managing postoperative nausea and vomiting. Anesth Analg 2003; 97: 62-71.
10. Apfel CC, Korttila K, Abdalla M, Kerger H, Turan A, Vedder I, et al. A factorial trial of six interventions for the prevention of postoperative nausea and vomiting. N Engl J Med 2004; 350: 2441-51.

11. Henzi I, Walder B, Tramer MR. Dexamethasone for the prevention of postoperative nausea and vomiting: a quantitative systematic review. Anesth Analg 2000; 90: 186-94.

12. Rhodes VA, McDaniel RW. The Index of Nausea, Vomiting, and Retching: a new format of the lndex of Nausea and Vomiting. Oncol Nurs Forum 1999; 26: 889-94.

13. Candiotti KA, Kovac AL, Melson TI, Clerici G, Joo Gan T. A randomized, double-blind study to evaluate the effi cacy and safety of three different doses of palonosetron versus placebo for preventing postoperative nausea and vomiting. Anesth Analg 2008; 107: 44551.

14. Jo YY, Lee JW, Shim JK, Lee WK, Choi YS. Ramosetron, dexamethasone, and their combination for the prevention of postoperative nausea and vomiting in women undergoing laparoscopic cholecystectomy. Surg Endosc 2012; 26: 2306-11.

15. Piper SN, Triem JG, Rohm KD, Kranke P, Maleck WH, Boldt J. Prevention of post-operative nausea and vomiting. Randomised comparison of dolasetron versus dolasetron plus dexamethasone. Anaesthesist 2003; 52: 120-6.

16. Rojas C, Li Y, Zhang J, Stathis M, Alt J, Thomas AG, et al. The antiemetic 5-HT3 receptor antagonist Palonosetron inhibits substance P-mediated responses in vitro and in vivo. J Pharmacol Exp Ther 2010; 335: 362-8.

17. Kovac AL, Eberhart L, Kotarski J, Clerici G, Apfel C. A randomized, double-blind study to evaluate the efficacy and safety of three different doses of palonosetron versus placebo in preventing postoperative nausea and vomiting over a 72-hour period. Anesth Analg 2008; 107: 439-44.

18. Rodseth RN, Gopalan PD, Cassimjee HM, Goga S. Reduced incidence of postoperative nausea and vomiting in black South Africans and its utility for a modified risk scoring system. Anesth Analg 2010; 110: 1591-4.

19. Yoon JS, Kim KM, Kim YH. The effects of amounts of intraoperative intravenous fluid administration on postoperative nausea and vomiting during gynecological surgery. Korean J Anesthesiol 2008; 55: 166-70.

20. Magner JJ, McCaul C, Carton E, Gardiner J, Buggy D. Effect of intraoperative intravenous crystalloid infusion on postoperative nausea and vomiting after gynaecological laparoscopy: comparison of 30 and $10 \mathrm{ml} \mathrm{kg(-1).} \mathrm{Br} \mathrm{J} \mathrm{Anaesth} \mathrm{2004;} \mathrm{93:} \mathrm{381-5.}$

21. Sinclair DR, Chung F, Mezei G. Can postoperative nausea and vomiting be predicted? Anesthesiology 1999; 91: 109-18. 